\title{
Age, growth, and natural mortality of yellowfin grouper (Mycteroperca venenosa) from the southeastern United States
}

Michael L Burton, Jennifer C Potts, Daniel R Carr

Ages of yellowfin grouper $(n=306)$ from the southeastern United States coast from 19792014 were determined using sectioned sagittal otoliths. Opaque zones were annular, forming January-June (peaking in February-March). Yellowfin grouper ranged in age from 3 - 31 years; the largest fish measured $1000 \mathrm{~mm}$ fork length (FL). Body size relationships for yellowfin grouper were: $W=1.22 \times 10^{-5} \mathrm{FL}^{3.03}\left(n=229, r^{2}=0.92\right) ; \mathrm{TL}=1.06 \mathrm{FL}-14.53(n=$ $\left.60, r^{2}=0.99\right) ;$ and $\mathrm{FL}=0.93 \mathrm{TL}+18.63\left(n=60, r^{2}=0.99\right)$, where $W=$ whole weight in grams, $\mathrm{FL}$ in $\mathrm{mm}$, and TL $=$ total length in $\mathrm{mm}$. The von Bertalanffy growth equation was: $L_{t}$ $=958\left(1-e^{-0.11(t+2.94)}\right)(n=306)$. Point estimates of natural mortality for yellowfin grouper were $M=0.14$, while age-specific estimates of $M$ ranged from $1.59-0.17$ for ages $1-31$. 
1 Age, growth, and natural mortality of yellowfin grouper (Mycteroperca venenosa) from the

2 southeastern United States

3

4 Michael L. Burton*

5 Jennifer C. Potts

6 Daniel R. Carr

7

8

9 Beaufort Laboratory

10 Southeast Fisheries Science Center

11 National Marine Fisheries Service, NOAA

12 Beaufort, North Carolina United States 28516-9701

13

*Mr. Burton: michael.burton@noaa.gov 252-728-8756; fax: 252-728-8784 


\section{ABSTRACT}

Ages of yellowfin grouper $(n=306)$ from the southeastern United States coast from 1979-2014 were determined using sectioned sagittal otoliths. Opaque zones were annular, forming JanuaryJune (peaking in February-March). Yellowfin grouper ranged in age from 3 - 31 years; the largest fish measured $1000 \mathrm{~mm}$ fork length (FL). Body size relationships for yellowfin grouper were: $W=1.22 \times 10^{-5} \mathrm{FL}^{3.03}\left(n=229, r^{2}=0.92\right)$; TL $=1.06 \mathrm{FL}-14.53\left(n=60, r^{2}=0.99\right)$; and $\mathrm{FL}=0.93 \mathrm{TL}+18.63\left(n=60, r^{2}=0.99\right)$, where $W=$ whole weight in grams, FL in mm, and TL $=$ total length in mm. The von Bertalanffy growth equation was: $L_{t}=958\left(1-e^{-0.11(\mathrm{t}+2.94)}\right)(n=$ 306). The point estimate of natural mortality for yellowfin grouper was $M=0.14$, while agespecific estimates of $M$ ranged from $1.59-0.17$ for ages $1-31$.

Subjects: Fisheries and Fish Science, Marine Biology

Keywords: Serranidae, Age and Growth, Life History, Natural Mortality

\section{INTRODUCTION}

The yellowfin grouper (Mycteroperca venenosa Linnaeus 1758), a moderate- to large-sized member of the family Serranidae, is widely distributed throughout the western Atlantic Ocean from North Carolina through the Florida Keys (referred hereafter as the southeastern US or SEUS), into the northern Gulf of Mexico, and in waters off Bermuda and throughout the Caribbean south to Brazil. Juveniles are often found in the shallow turtle grass (Thalassia testudinum) beds, while adults are typically found on subtropical rocky hardbottom and coral reef areas at depths up to $137 \mathrm{~m}$ (Heemstra \& Randall, 1993). Yellowfin grouper feed mainly on fishes and squid (Randall, 1967) and are known to form spawning aggregations (Kadison et al., 
2010; Scharer et al., 2012). Cushion (2010) studied growth and reproduction of specimens from the Bahamas.

Yellowfin grouper are of moderate importance to the SEUS reef fish fishery. While caught infrequently by anglers, their large size makes them a prized trophy species. Estimated total annual landings from headboats (vessels carrying at least seven anglers engaged in recreational fishing) sampled by the Southeast Region Headboat Survey (SRHS), conducted by the National Marine Fisheries Service (NMFS), averaged 304 kg from 1986 - 2013 (K Brennan, 2014, unpublished data). Annual numbers of fish landed by anglers fishing from private recreational boats and charter boats, estimated by the NMFS Marine Recreational Information Program (MRIP, T Sminkey, 2014, unpublished data) averaged 649 fish from 1981 - 2013. Commercial fisheries of the SEUS on average annually harvested $2163 \mathrm{~kg}$ of yellowfin grouper from 1981 - 2013 (N Baertlein, SEFSC, Miami, FL, pers.comm. 2014), primarily from hookand-line gear. Landings are widely distributed along the SEUS coast, from North Carolina through the Florida Keys, including the Dry Tortugas.

Yellowfin grouper are currently included in the South Atlantic Fishery Management Council's (SAFMC) Snapper-Grouper Fishery Management Plan (FMP). Since 1992 the species has been regulated by a 20 inch $(508 \mathrm{~mm})$ total length (TL) size limit in commercial and recreational fisheries; they have been included in a shallow-water grouper closed season from January 1 - April 30 of each year since 2012, and included in an aggregate three-grouper-perperson-per-day bag limit for recreational fishermen outside of the closed season since 2012 (five grouper bag limit during 1992 - 2011) (SAFMC, 2015). Commercial regulations include the 20 inch size limit and inclusion in the shallow-water grouper closure from January 1 - April 30 (SAFMC, 2015). Yellowfin grouper are not currently scheduled for a National Marine Fisheries 
Service (NMFS) stock assessment under the Southeast Data, Assessment and Review (SEDAR) program, likely due to low annual landings and management priorities.

Information about size-at-age and growth rates of reef fishes is important to fishery managers. The preferred method of aging reef fish is to use the sagittal otoliths, or ear stones (Manooch, 1987), a calcareous structure found inside the cranium. These sagittae may be read as whole structures but are usually sectioned into several thin sections and the sections looked at under a microscope to elucidate the age of the fish. Age is determined by counting alternating opaque and translucent bands deposited due to fluctuations in environmental conditions such as water temperature. Nonlinear regression relating the measured length of the fish to the estimated age leads to the generation of growth curves, which are one of the most important inputs into the stock assessment process used by NMFS to manage fisheries (K. Siegfried, NMFS Beaufort Laboratory, pers. comm. 2015).

We studied yellowfin grouper because little is known of their life history in SEUS waters. The desirability of the species as a trophy fish for recreational angles due to its large size, the relative infrequency with which it is caught, and the potential for overexploitation by overfishing spawning aggregations all make it imperative to study the basic biology needed for proper fishery management. Herein, we describe age and growth parameters and natural mortality, which are important input variables for agency-led stock assessment efforts. This study provides the first published information on life history parameters for yellowfin grouper from SEUS waters. 
93 Yellowfin grouper $(n=308)$ were opportunistically sampled by NMFS and state agencies' port

94 agents sampling the recreational headboat and commercial fisheries in the SEUS from 1979 -

95 2014. All specimens used in this study were killed as part of legal fishing operations

96 and were already dead when sampled by the port agents, thus all research was conducted in

97 accordance with the Animal Welfare Act (AWA) and with the U.S. Government Principles

98 for the Utilization and Care of Vertebrate Animals Used in Testing, Research, and Training

99 (USGP) OSTP CFR, May 20, 1985, Vol. 50, No. 97. All specimens were captured by either

100 conventional vertical hook and line gear or longline gear. Fork lengths (FL) and TL of

101 specimens were recorded in millimeters $(\mathrm{mm})$. Whole weight $(\mathrm{W})$ in grams $(\mathrm{g})$ was recorded for

102 fish landed in the headboat fishery, but information about sex was not routinely recorded due to

103 time constraints. Fish landed commercially were eviscerated at sea, thus whole weights and

104 information about sex were unavailable. Sagittal otoliths were removed during dockside

105 sampling and stored dry in coin envelopes. Otoliths were sectioned in the transverse dorso-

106 ventral plane on a low-speed saw, following the methods of Potts \& Manooch (1995). Three

107 serial $0.5 \mathrm{~mm}$ sections were taken near the otolith core. Sections were mounted on microscope

108 slides with thermal cement and covered with mounting medium before analysis. The sections

109 were viewed under a dissecting microscope at $12.5 \mathrm{X}$ using transmitted light. Each sample was

110 assigned an opaque zone, or ring, count by an experienced reader (MLB) (Burton 2001, 2002;

111 Burton, Potts \& Carr, 2012). Sections were read with no knowledge of date of capture or fish

112 size. To ensure consistency between readers in the interpretation of growth structures, a second

113 reader (JCP) read a subset $(n=102)$ of slides, then we calculated between-reader indices of

114 average percent error (APE) following the methodology of Beamish and Fournier (1981). When

115 annuli counts differed between paired readings, the initial reading was used. 
117 noted: 1 = opaque zone forming on the edge of the otolith section; 2 = narrow translucent zone

118 on the edge, generally $<30 \%$ of the width of the previous translucent zone; $3=$ moderate

119 translucent zone on the edge, generally $30 \%-60 \%$ of the width of the previous translucent zone;

1204 = wide translucent zone on the edge, generally $>60 \%$ of the width of the previous translucent

121 zone (Harris et al., 2007). Based upon edge frequency analysis, all samples were assigned a

122 calendar age, obtained by increasing the opaque zone count by one if the fish was caught before

123 that year's increment was formed and had an edge which was a moderate to wide translucent

124 zone (types 3 and 4). Fish caught during the time of year of opaque zone formation with an edge

125 type of 1 or 2 were assigned a calendar age equal to opaque zone count. All fish caught after

126 opaque zone formation would have a calendar age equivalent to the opaque zone count.

\section{Growth}

128 Von Bertalanffy (1938) growth parameters were derived using PROC NLIN, a non-linear regression procedure using least squares estimation and the Marquardt iterative algorithm option, in SAS statistical software (vers. 9.3; SAS Institute, 1987). If the residuals of the un-weighted model appeared skewed at the tails of the sample distribution, we inverse-weighted the model by $1 / n$ of each calendar age. Given studies showing that peak spawning of yellowfin grouper occurs March-April in the Bahamas and Caribbean (Smith, 1961; Thompson \& Munro, 1978; Cushion, account for growth of the fish throughout the year before or after its "birthday", the calendar age

$$
\mathrm{Age}_{\mathrm{f}}=\mathrm{Age}_{\mathrm{c}}+\left(\left(\mathrm{Mo}_{\mathrm{c}}-\mathrm{Mo}_{\mathrm{b}}\right) / 12\right)
$$




\section{Body-Size Relationships}

141 For weight-length relationships, we regressed W on TL $(n=229)$ and FL $(n=59)$, examining

142 both a non-linear fit by using nonlinear least squares estimation (SAS Institute, 1987) and a

143 linearized fit of the log-transformed data, examining the residuals to determine which regression 144 was appropriate. For length-length relationships, we regressed TL on FL and FL on TL $(n=60)$

145 using linear regression.

146 Natural Mortality

147 We estimated the instantaneous rate of natural mortality $(M)$ using two methods:

148 (1) Hewitt \& Hoenig’s (2005) longevity mortality relationship:

$149 M=4.22 / t_{\max }$

150 where $t_{\max }$ is the maximum age of the fish in the sample, and

151 (2) Charnov, Gislason and Pope's (2013) method using life history parameters:

$152 M=\left(L / L_{\infty}\right)^{-1.5} \times K$

153 where $L_{\infty}$ and $K$ are the von Bertalanffy growth equation parameters, when $\mathrm{t}_{0}$ is assumed to be 0 , 154 and $L$ is fish length at age. The Hewitt and Hoenig (2005) method uses longevity to generate a 155 single point estimate. The Charnov method, which incorporates life history information via 156 estimated growth parameters, is based upon evidence suggesting that $M$ decreases as a power 157 function of body size. This method generates age-specific rates of $M$ and is currently in use in 158 SEDAR stock assessments (E Williams, NMFS Beaufort Laboratory, pers comm. 2013).

\section{RESULTS}

161 Age determination and timing of opaque zone formation 
162 A total of 308 sagittal otoliths of yellowfin grouper were sectioned. The distribution by area 163 and fishery sector of samples used in the age analysis is shown in Table 1. The majority of 164 samples came from the Carolinas $(n=277)$ with most $(n=259)$ from commercial fisheries

165 (Table 1). The remaining samples $(n=31)$ came from Florida. We assigned an opaque zone 166 count to 306 (99\%) yellowfin grouper sections. Two specimens were excluded because sections 167 were illegible.

168 We assigned an edge type to all readable samples for our analysis of increment 169 periodicity. Yellowfin grouper deposited opaque zones on the otolith marginal edge January 170 through June (Fig. 1), with peak formation in February and March. A transition to a narrow 171 translucent edge occurred beginning in May. Yellowfin grouper otoliths were without an opaque 172 zone on the edge from July through December. The widest translucent edges occurred 173 November and December, prior to opaque zone formation in January. We concluded that opaque 174 zones on yellowfin grouper otoliths were annuli. Calendar ages based on edge analysis were

175

176 assigned as follows: for fish caught January through June and having edge types of 3 and 4, the annuli count was increased by one; for fish caught in that same time period with edge types 1 and 2, as well as for fish caught from July to December, the calendar age was equivalent to the annuli count.

Yellowfin grouper annuli were relatively easy to interpret (Fig. 2). Agreement was good between readers for otolith sections from yellowfin grouper. Average percent error, or APE, was $3.32 \%(n=102)$, which is less than Campana's (2001) threshold level of acceptability of $5 \%$ for species of moderate longevity and reading complexity. Direct agreement between readings was moderate (44\%), and agreement for \pm 1 year was $83 \%$. The largest discrepancy between readings was a difference of three, for a 16 year old fish. 
186 Yellowfin grouper in this study ranged from $405-1000 \mathrm{~mm}$ FL and ages 3 - 31, although only

18712 fish were older than age-19 (Table 2). The resulting von Bertalanffy growth equation for the 188 unweighted, freely-estimated model was:

$$
L_{t}=958\left(1-\mathrm{e}^{-0.11(\mathrm{t}+2.94)}\right)(n=306 ; \text { Fig. } 3) \text {. }
$$

190 Predicted size-at-age from this model run agreed well with mean observed size-at-age (Fig. 4).

191 Fish less than age-3 were unavailable to us, no doubt because hook-and-line gear generally select

192 for larger fish and the minimum size limit regulations excluded the smaller fish from the

193 landings. Consequently, the model was unable to depict initial growth of young fish, thus

194 explaining the moderately negative value of $t_{0}$. Therefore, we re-estimated the growth models 195 using a fixed value of $t_{0}=-0.5$ (Burton, Potts \& Carr, 2012), which has the effect of pulling the 196 growth curve down to simulate smaller fish length at age for the youngest ages. The value of 1970.5 was selected to approximate growth of age- 0 fish, which is an annual age that encompasses 198 twelve months. This modelling procedure is currently in use in SEDAR stock assessments 199 (SEDAR, 2013) for species that either have a regulatory minimum size limit or exhibit size 200 selectivity toward fishing gear. The model was inverse weighted to adjust for the lower limb of 201 the curve being pulled down. The residuals for the largest, oldest fish were more evenly 202 distributed in this model. The resulting growth model is:

$$
L_{t}=929\left(1-e^{-0.156(t+0.5)}\right),(n=306 ; \text { Fig. 3). }
$$

In 1992 a 20-inch (508 mm) minimum size limit enacted for yellowfin grouper excluded smaller 205 fish from the landings and thus our samples. We re-ran the growth model using the method of McGarvey \& Fowler (2002), which adjusts for the bias imposed by minimum size limits by 
207

208

209

210

211

212

213

214

215

216

217

218

219

220

221

222

223

224

225

226

227

228

229

assuming zero probability of capture below the minimum size limit. The resulting von

Bertalanffy growth equation was:

$$
L_{t}=966\left(1-e^{-0.13(t+2.48)}\right)(n=305 ; \text { Fig. } 3) \text {. }
$$

\section{Body-size relationships}

Statistical analyses revealed a multiplicative error term (variance increasing with size) in the residuals of the $W-\mathrm{TL}$ and $W-\mathrm{FL}$ relationships for yellowfin grouper, indicating a linearized ln-transform fit of the data was appropriate. The relationships are described by the following regressions:

$$
\begin{aligned}
& \ln (W)=3.026 \times \ln (\mathrm{TL})-11.345\left(n=229, r^{2}=0.92\right) \\
& \ln (W)=2.915 \times \ln (\mathrm{FL})-10.453\left(n=59, r^{2}=0.98\right)
\end{aligned}
$$

These equations were transformed back to the form $W=a(\mathrm{~L})^{b}$ after adjusting the intercept for log-transformation bias with the addition of one-half of the mean square error (1/2 MSE) (Beauchamp \& Olsen, 1973), resulting in the relationships

$$
\begin{aligned}
& W=1.22 \times 10^{-5} \mathrm{TL}^{3.03} \text { and } \\
& W=2.89 \times 10^{-5} \mathrm{FL}^{2.91} .
\end{aligned}
$$

The relationships between TL and FL are described by the equations

$$
\begin{aligned}
& \mathrm{TL}=1.06 \times \mathrm{FL}-14.53\left(n=60 ; r^{2}=0.99\right) \text { and } \\
& \mathrm{FL}=0.93 \times \mathrm{TL}+18.63\left(n=60 ; r^{2}=0.99\right) .
\end{aligned}
$$

\section{Natural mortality}

Natural mortality $(M)$ was estimated at 0.14 using the method of Hewitt \& Hoenig (2005), integrating all ages into a single point estimate and using the maximum age from our study of age 31. Because Charnov, Gislason \& Pope's (2013) age-specific calculation of $M$ assumed a von Bertalanffy growth function with $t_{0}=0$, we re-estimated $K$ and $L_{\infty}$ with the constraint $t_{0}=0$, 
and inverse weighting the model. The resulting parameters were $L_{\infty}=921 \mathrm{~mm} \mathrm{TL}$ and $K=0.17$. Age-specific estimates of $M$ using Charnov, Gislason \& Pope (2013) are presented in Table 2. We used the midpoint of each age (e.g., $0.5,1.5,2.5$, etc.) to calculate age-specific $M$, because the Charnov, Gislason \& Pope (2013) method cannot mathematically calculate $M$ for absolute age-0. Also, for stock assessment purposes where the integer age is used to describe the entire year of the fish's life, the mid-point gives the median value of $M$ for that age.

\section{DISCUSSION}

Otolith edge analysis demonstrated that yellowfin grouper deposited one annulus per year between January and June, with peak annulus formation between February and March. This is similar to timing of annulus formation for other groupers in the SEUS, which tend to form annuli in winter (Moe 1969; Manooch \& Haimovici, 1978; Burton, Potts and Carr, 2012). Crabtree \& Bullock (1998) found that the congeneric black grouper (Mycteroperca bonaci), formed annuli from April-June in Florida waters.

Yellowfin grouper grew moderately fast, attaining an average observed size of $428 \mathrm{~mm}$ FL by age- $3,583 \mathrm{~mm}$ by age- $5,736 \mathrm{~mm}$ by age- 10 , and $821 \mathrm{~mm}$ by age- 15 . Subsequently, growth slowed to an average of $14 \mathrm{~mm}$ per year (Table 2). Observed size at age for yellowfin grouper from the SEUS compared favorably through age-13 with that of the Bahamian population studied by Cushion (2010) (Fig. 3) but our study found a much greater maximum age than that found by Cushion (2010), 31 yrs as compared with 13 yrs for the Bahamian population. While both studies were comprised of fishery-dependent samples, we feel our study was more representative of the population we sampled due to broader geographic coverage and larger 
252 sample size. All of the samples from the Bahamas study came from a single fish-market in New

253 Providence Island.

254 Our predicted growth curve of yellowfin grouper using the parameters from the freely

255 estimated, unweighted growth model fit the observed data well (Fig. 4). The von Bertalanffy

256 parameter $K$, or the Brody growth coefficient, which estimates the rate of attainment of

257 maximum size, was lower in our study, 0.11 , compared to 0.14 for Bahamian yellowfin grouper

258 (Cushion 2010). Conversely, maximum predicted length was slightly larger for Bahamian fish

$259(977 \mathrm{~mm})$ versus our study $(958 \mathrm{~mm})$, which is interesting considering maximum observed ages

260 were age-13 and age-31, respectively. Curiously, the usual expectation is that tropical

261 populations of fish grow faster and reach smaller maximum sizes and ages than subtropical or

262 temperate populations (Longhurst \& Pauly 1987; Berrigan \& Charnov 1994). Manickchand-

263 Heileman \& Phillip (2000) pointed out that yellowmouth grouper (Mycteroperca interstitialis)

264 populations from Trinidad and Tobago had larger maximum sizes, lower growth rates, and

265 greater observed age when compared with subtropical/temperate populations. They suspected

266 that this was likely because of a shorter period of exploitation. Relatively high rates of fishing

267 pressure in the tropics may tend to truncate the population age structure of yellowfin grouper in

268 the Bahamas. Alternately, we examined almost four times as many specimens as Cushion

269 (2010). Perhaps with a greater sample size there is a greater chance of encountering fish of

270 greater ages; Hoenig (1983) recognized this possibility and incorporated sample size into his

271 estimator for mortality rates.

272 We constrained $t_{0}$ to -0.5 in our modified growth curve for yellowfin grouper, which had

273 the effect of dampening the growth curve in the earliest years. However, by age- 6 the modified

274 curve and the freely estimated curve were nearly identical, differing only in the earlier ages. 
275 Adjustment of the curve for size limits using the method of McGarvey \& Fowler (2005) resulted

276 in very similar growth parameters as generated by the freely estimated model. While size at age-

2771 was slightly lower, the method did not pull the curve down in the earlier ages as much as the

278 previous fixed $t_{0}$ model run did, and the von Bertalanffy growth parameters were very similar

279 (Fig. 3). This result is likely explained by the fact that there were very few fish in the age classes

280 most affected by the size limit prior to the implementation of the minimum size limit. Thus the

281 McGarvey \& Fowler (2005) method could not fully determine and correct for the potential non-

282 normal distribution of size-at-age.

283 Natural mortality $(M)$ of wild fish populations is difficult to measure but is an important

284 input into stock assessments. A point estimate of $M$ (Hewitt \& Hoenig, 2005) for the entire life

285 span of a fish seems unreasonable, because as fish grow they become less vulnerable to

286 predation. We thought that our point estimate of $M$ was reasonable for fully recruited ages in our

287 study but was an insufficient estimate of $M$ for all ages. The age-varying $M$ calculated using

288 Charnov, Gislason and Pope (2013) seems a more appropriate estimator for the younger ages.

289 The initial Charnov estimates of $M$ starting with the fully recruited age- 6 are approximately $2.6 \mathrm{x}$

290 the Hewitt and Hoenig estimate, reflecting higher natural mortality at younger ages. The age-

291 specific estimates of $M$ for the older ages stabilized near the Hewitt \& Hoenig (2005) estimate of

$292 M$ (Table 2). When considering the cumulative estimate of survivorship to the fully recruited

293 ages, the Hewitt \& Hoenig (2005) method estimated 2.9\% survivorship, while the Charnov

294 estimate was $0.6 \%$. Very few of the fish in our samples were older than age-18 (19 of 306), and

295 even fewer were older than age-22 $(n=4)$. Though sample size in this study was limited, the

296 age-frequency distribution suggests that the chance of survivorship to the oldest age may truly be

297 as low as $1 \%$. There is no evidence that hook and line gear is dome-selective for this species or 
298 its congeners: thus our study had the potential to collect the largest and oldest fish in the

299 population. These observations give weight to the argument to use Charnov's estimate of $M$ at 300 age.

301 One limitation of this study was the lack of fish smaller than about $428 \mathrm{~mm}$ FL (or about 302 age-3), because of the fishery-dependent nature of our samples, the selectivity of fishing gear, 303 and the minimum size limits in place for yellowfin grouper. Lack of smaller fish is common in 304 studies dominated by fishery-dependent samples and can lead to problems in estimating the 305 growth curve for the youngest ages. Inclusion of fishery-independent samples usually corrects 306 this problem, as fishery-independent gear such as traps will catch smaller fish. However, only 307 two yellowfin grouper have been caught by the two major fishery-independent surveys operated

308 by natural resource agencies in the southeast (Southeast Fishery Independent Survey, 309 administered by the NOAA Fisheries/SEFSC/Beaufort Laboratory, 2010-present; Marine

310 Monitoring, Assessment and Prediction Program annual survey, administered by South Carolina

311 Department of Natural Resources, 1972-present). Younger fish were unavailable to us to help

312 define the trajectory of the growth curve at the earliest ages, and this section of the growth curve

313 should be interpreted with caution. We accounted for this limitation by re-estimating our growth

314 parameters using a fixed value for $t_{0}$ of -0.5 .

315 Another limitation of our study is the long period of time over which samples were 316 collected (> 30 yrs). Population parameters can vary inter-annually for various reasons (e. g.,

317 variable recruitment, environmental reasons), and it is certain that parameter estimates based on 318 samples collected over 30 yrs would have increased variability when compared to estimates 319 generated from samples collected over a much shorter time period. Unfortunately, samples from 
320 infrequently-caught species such as yellowfin grouper will likely never be obtained in quantities

321 large enough to allow us to eliminate this source of error in the parameter estimates.

\section{CONCLUSIONS} have shown that otolith sections of yellowfin grouper contain annuli that are relatively easy to enumerate and that otolith sections are therefore likely reliable structures for aging. Growth rings on yellowfin grouper sagittae are assumed to be deposited once a year in spring and growth is generally fast for the first seven years and then slows considerably, as evidenced by the low value of $K$, the von Bertalanffy growth coefficient. Our estimates of $M$ are reasonable for a fish with a moderately long life span and longevity to age 31 . We believe the results of this study accurately describe the fished population of yellowfin grouper in the SEUS. The overall landings of this species in the commercial and recreational fisheries of the SEUS make it an unlikely candidate for a stock assessment through the NMFS SEDAR process because of the prioritization of more commonly landed species. A possible use of these data would be their application to studies of the population dynamics of U. S. Caribbean stocks (U. S. Virgin Islands and Puerto Rico). The U. S. Caribbean is typically a data poor region and studies from the SEUS could be used as proxies in analyses for the region. However, analyses should be undertaken to determine appropriateness of such a procedure (i.e., similar life history traits between populations). Application of the growth curve from Cushion's (2010) Bahamian population to populations from the wider Caribbean might not be warranted based on the low maximum age in

341 her study vs. what the current study found. Precaution should always be taken when

342 extrapolating beyond the scope of current data. 
Acknowledgements

347 We gratefully acknowledge the many headboat and commercial port samplers over the years whose efforts made this study possible. J. Smith, R. Cheshire, T. Kellison and two anonymous reviewers provided valuable reviews that greatly improved the manuscript.

\section{REFERENCES}

Beamish RJ, Fournier DA. 1981. A method for comparing the precision of a set of age determinations. Canadian Journal of Fisheries and Aquatic Science 38:982-983. transformations. Ecology 54:1403-1407. doi: 10.2307/1934208.

Berrigan D, Charnov EL. 1994. Reaction norms for age and size at maturity in response to temperature: a puzzle for life historians. Oikos 70:474-478.

Burton ML. 2001. Age, growth, and mortality of gray snapper from the east coast of Florida. Fishery Bulletin. 99:245-256.

Burton ML. 2002. Age, growth and mortality of mutton snapper, Lutjanus analis, from the east coast of Florida, with a brief discussion of management implications. Fisheries Research 
59: 31-41.

367

368

369

370

371

372

373

374

375

376

377

378

379

380

381

382

383

384

385

386

Burton ML, Potts JC, Carr DR. 2012. Age, growth and natural mortality of rock hind, Epinephelus adscencionis, from the Gulf of Mexico. Bulletin of Marine Science 88: 903917.

Campana SE. 2001. Accuracy, precision and quality control in age determination, including a review of the use and abuse of age validation methods. Journal of Fish Biology 59:197242. doi: 10.1111/j.1095-8649.2001.tb00127.x.

Charnov EL, Gislason H, Pope JG. 2013. Evolutionary assembly rules for fish life histories. Fish and Fisheries 14:212-224. doi: 10.1111/j.1467-2979.2012.00467.x.

Crabtree RE, Bullock LH. 1998. Age, growth and reproduction of black grouper, Mycteroperca bonaci, in Florida waters. Fishery Bulletin 96:735-753.

Cushion NM. 2010. Growth, reproductive life-history traits and energy allocation in Epinephelus guttatus (red hind), E. striatus (Nassau grouper), and Mycteroperca venenosa (yellowfin grouper) (Family Serranidae, Subfamily Epinephelinae). M. Sc. Thesis, University of Miami, Miami, FL. 
387 Harris PJ, Wyanski DM, White DB, Mikell PP, Eyo PB. 2007. Age, growth, and

388

389

390

391

392

393 reproduction of greater amberjack off the southeastern U.S. Atlantic coast. Transactions of the American Fisheries Society 136:1534-1545.

Heemstra PC, Randall JE. 1993. 1993 FAO Species Catalogue. Vol. 16. Groupers of the world (Family Serranidae, Subfamily Epinephelinae): an annotated and illustrated catalogue of the grouper, rockcod, hind, coral grouper and lyretail species known to date. FAO Fisheries Synopsis. Food and Agricultural Organization, Rome.

Hewitt DA, Hoenig JM. 2005. Comparison of two approaches for estimating natural mortality based on longevity. Fishery Bulletin 103:433-437.

Hoenig JM. 1983. Empirical use of longevity data to estimate mortality rates. Fishery Bulletin 81:898-903.

Kadison E, Nemeth R, Brown-Peterson N, Blondeau J, Smith T, Calnan J. 2010. Yellowfin grouper (Mycteroperca venenosa): Reproductive biology, behavior and conservation of a large Caribbean grouper. Proceedings of the Gulf and Caribbean Fisheries Institute 63:157-160.

Longhurst AR, Pauly D. 1987. Ecology of Tropical Oceans. Academic Press, London. 
409

410

411

412

413

414

415

416

417

418

419

420

421

422

423

424

425

426

427

428

429

430

431

Manickchand-Heileman SC, Phillip DAT. 2000. Age and growth of the yellowedge grouper, Epinephelus flavolimbatus, and the yellowmouth grouper, Mycteroperca interstitialis, off Trinidad and Tobago. Fishery Bulletin 98:290-298.

Manooch, CS III. 1987. Age and growth of snappers and groupers. In: Polovina JJ, Ralston S, ed. Tropical snappers and groupers: biology and fisheries management. Boulder CO: Westview Press.

Manooch CS III, Haimovici M. 1978 Age and growth of the gag, Mycteroperca microlepis, and size-age composition of the recreational catch off the southeastern United States. Transactions of the American Fisheries Society 107:234-240.

McGarvey R, Fowler AJ 2002. Seasonal growth of King George whiting (Sillaginodes punctata) estimated from length-at-age samples of the legal-size harvest. Fishery Bulletin 100:545-558.

Moe MA. 1969. Biology of the red grouper Epinephelus morio (Valenciennes) from the eastern Gulf of Mexico. Florida Department of Natural Resources Marine Research Laboratory Professional Paper Series 10, 95 p.

Potts JC, Manooch CS III. 1995. Age and growth of red hind and rock hind collected from North Carolina through the Dry Tortugas, Florida. Bulletin of Marine Science 56:784794. 
Randall JE 1967. Food habits of reef fishes of the West Indies. Studies in Tropical Oceanography (Miami) 5:665-847.

435

436

437

438

439

440

441

442

443

444

445

446

447

448

449

450

451

452

453

454

SAFMC 2015. South Atlantic Fishery Management Council. Yellowfin Grouper. Available at: http://safmc.net/fish-id-and-regs/yellowfin-grouper. Accessed via the internet April 30, 2015.

SAS Institute, Inc. 1987. SAS/STAT guide for personal computers, vers. 6, 378 p. SAS Institute, Inc., Cary, NC.

Scharer MT, Nemeth MI, Mann D, Locascio J, Appeldoorn RS, Rowell TJ. 2012. Sound production and reproductive behavior of yellowfin grouper, Mycteroperca venenosa (Serranidae) at a spawning aggregation. Copeia 2012:135-144.

SEDAR 2013. SEDAR 32 - South Atlantic blueline tilefish Stock Assessment Report. SEDAR, N. Charleston, SC. 378 pp. Available from http://sedarweb.org/docs/sar/S32_SABLT SAR FINAL 11.26.2013.pdf Accessed via the internet May 26, 2015.

Smith CL. 1961. Synopsis of biological data on groupers (Epinephelus and allied genera) of the western North Atlantic. Food and Agricultural Organization Fisheries Biology Synopsis No. 23. $62 \mathrm{p}$. 
455 Thompson R, Munro J. 1978. Aspects of the biology and ecology of Caribbean reef fishes: Serranidae (hinds and groupers). Journal of Fish Biology 12:115-146.

von Bertalanffy, L. 1938. A quantitative theory of organic growth (inquiries on growth laws II). Human Biology 10:181-243.

460

461

462

463

464

465

466

467

468

469

470

471

472

473

474

475

476

477 


\section{Figure Captions}

Figure 1. Monthly percentage of edge types on yellowfin grouper Mycteroperca venenosa otoliths $(n=306)$. Edge codes: $1=$ opaque zone on edge; $2=$ small translucent zone, $<30 \%$ of previous increment; $3=$ moderate translucent, $30 \%-60 \%$ of previous increment; $4=$ wide translucent, $>60 \%$ of previous increment.

Figure 2. Sections from otoliths of yellowfin grouper Mycteroperca venenosa: A. 720 mm FL, age 12 yrs: B. $915 \mathrm{~mm}$ FL, age 17 yrs. Age was determined by counting opaque increments along the dorsal axis and sulcus using transmitted light at $12.5 \mathrm{X}$ magnification.

Figure 3. Comparison of SEUS yellowfin grouper von Bertalanffy growth curves for freely estimated (unweighted),$t_{0}$-restrained at -0.5 , and size limit-corrected model runs (McGarvey Fowler, 2002). Growth model from the Bahamas population (Cushion 2010) is presented for comparison.

Figure 4. Comparison of mean observed size at age (yrs) and sizes predicted by the von Bertalanffy freely-estimated growth model for yellowfin grouper Mycteroperca venenosa from the southeastern U. S. 
Figure 1 (on next page)

Otolith edge analysis to determine timing of opaque zone formation.

Monthly percentage of edge types on yellowfin grouper Mycteroperca venenosa otoliths ( $n=$ 306). Edge codes: 1 = opaque zone on edge; 2 = small translucent zone, $<30 \%$ of previous increment; $3=$ moderate translucent, $30 \%-60 \%$ of previous increment; $4=$ wide translucent, $>60 \%$ of previous increment. 


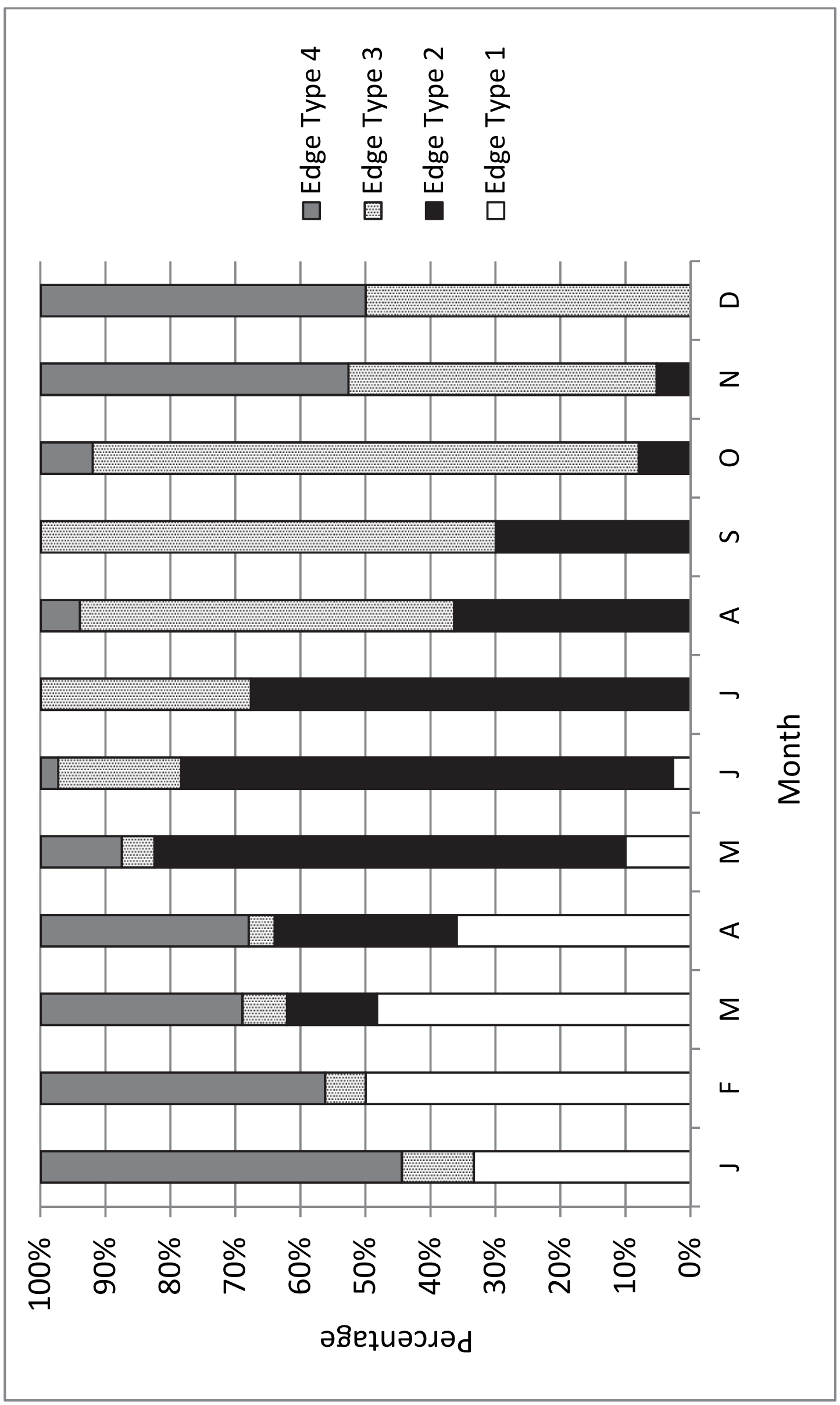


Figure 2 (on next page)

Photographs of sections from two yellowfin grouper.

Sections from otoliths of yellowfin grouper Mycteroperca venenosa: A. $720 \mathrm{~mm} \mathrm{FL,} \mathrm{age} 12$

yrs: B. $915 \mathrm{~mm} \mathrm{FL}$, age 17 yrs. Age was determined by counting opaque increments along the dorsal axis and sulcus using transmitted light at $12.5 \mathrm{X}$ magnification. 

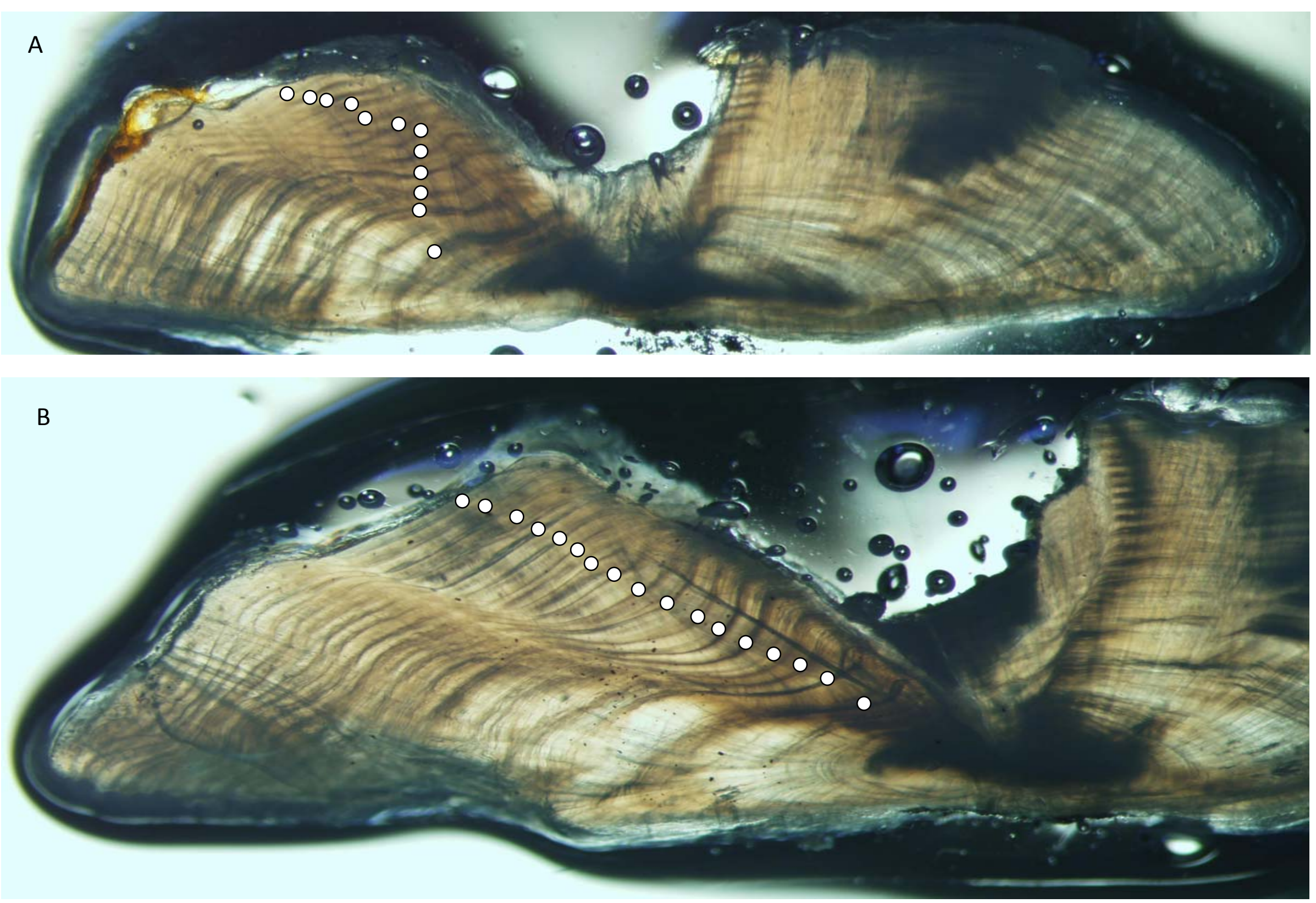
Figure $\mathbf{3}$ (on next page)

Comparison of theoretical growth of yellowfin grouper from various studies.

Comparison of SEUS yellowfin grouper von Bertalanffy growth curves for freely estimated (unweighted) , $t_{0}$-restrained at -0.5, and size limit-corrected model runs (McGarvey Fowler, 2002). Growth model from the Bahamas population (Cushion 2010) is presented for comparison. 


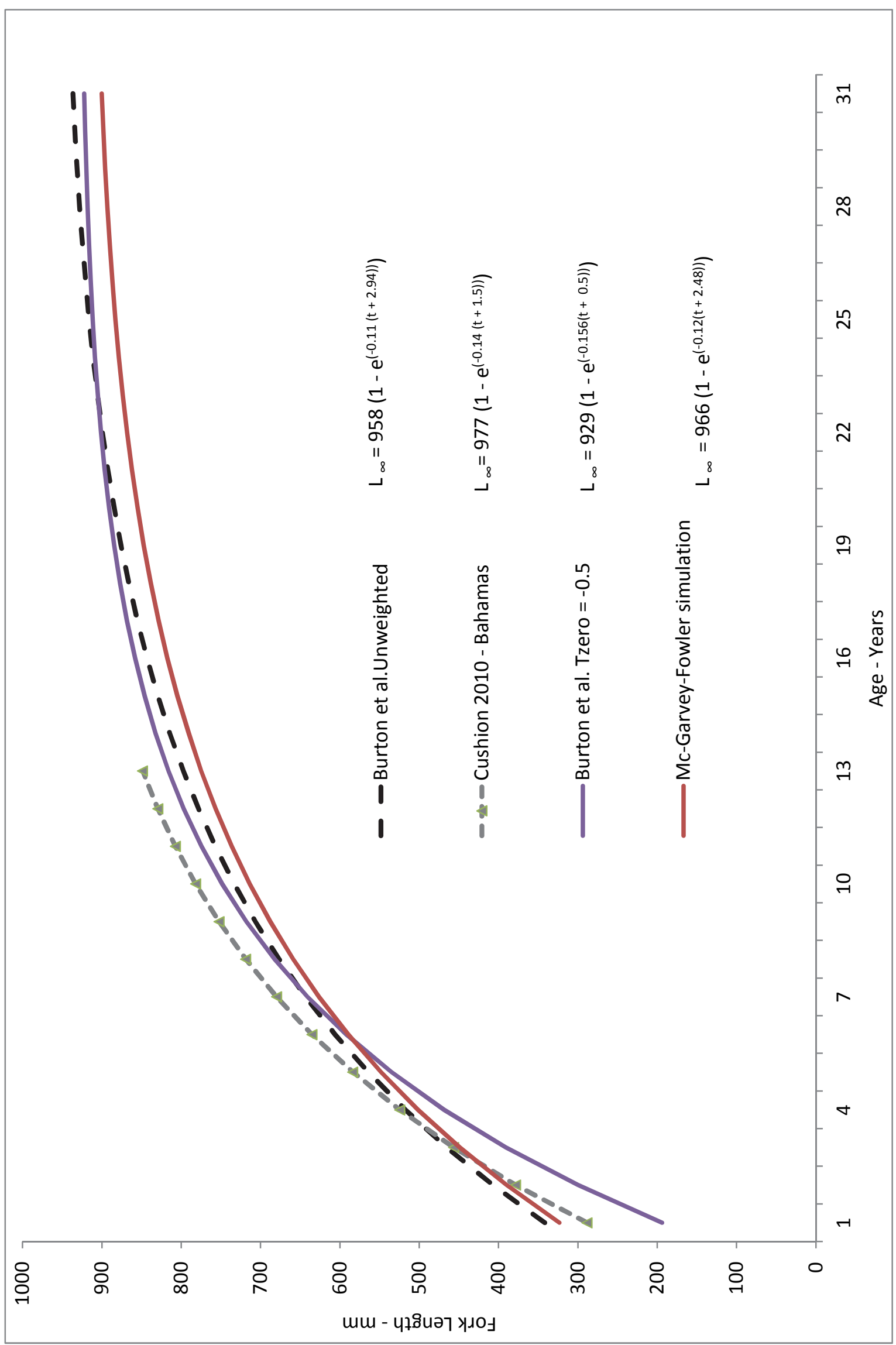


Figure 4 (on next page)

Comparison of observed and predicted size-at-age for yellowfin grouper from the current study.

Comparison of mean observed size at age (yrs) and sizes predicted by the von Bertalanffy freely-estimated growth model for yellowfin grouper Mycteroperca venenosa from the southeastern U. S. 


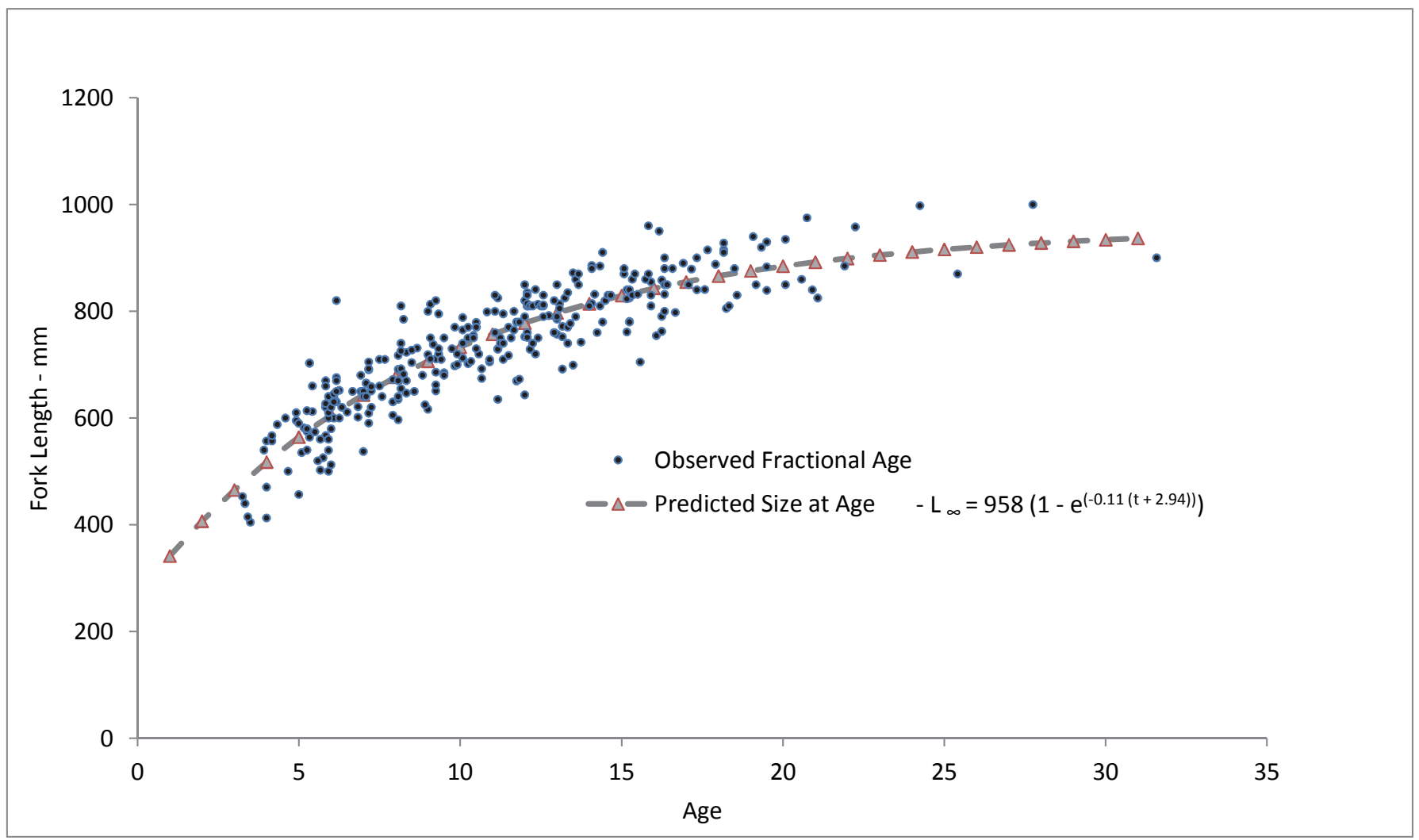




\section{Table $\mathbf{1}_{\text {(on next page) }}$}

Table 1. Geographic and fishery sector distribution of yellowfin grouper aging study.

Number of samples of sagittal otoliths that were used for age and growth study of yellowfin grouper (Mycteroperca venenosa) collected from 1979-2014 from fisheries landings along the coast of the southeastern United States. Samples were collected in the following states: North Carolina (NC), South Carolina (SC), and Florida (FL). 
1 Table 1. Number of samples of sagittal otoliths that were used for age and growth study of

2 yellowfin grouper (Mycteroperca venenosa) collected from 1979-2014 from fisheries landings

3 along the coast of the southeastern United States. Samples were collected in the following states:

4 North Carolina (NC), South Carolina (SC), and Florida (FL).

\begin{tabular}{lrr}
\hline State & Commercial & Recreational \\
\hline $\mathrm{NC}$ & 134 & 3 \\
$\mathrm{SC}$ & 125 & 15 \\
$\mathrm{FL}$ & 3 & 28 \\
\hline
\end{tabular}

5 
Table 2 (on next page)

Age-specific observed and predicted size and natural mortality for yellowfin grouper from the SEUS.

Observed and predicted mean fork length (FL) from the freely estimated growth model, measured in millimeters, and natural mortality at age ( $M$, Charnov et al, 2013) data for yellowfin grouper (Mycteroperca venenosa) collected from 1979-2014 along the coast of the southeastern United States. Standard errors of the means (SE) are provided in parentheses. 
1 Table 2. Observed and predicted mean fork length (FL) from the freely estimated growth model,

2 measured in millimeters, and natural mortality at age ( $M$, Charnov et al, 2013) data for yellowfin

3 grouper (Mycteroperca venenosa) collected from 1979-2014 along the coast of the southeastern

4 United States. Standard errors of the means (SE) are provided in parentheses.

\begin{tabular}{|c|c|c|c|c|c|}
\hline Age & $n$ & Mean FL $( \pm \mathrm{SE})$ & FL range & $\begin{array}{c}\text { edict } \\
\text { FL }\end{array}$ & $M$ \\
\hline 1 & & & & 308 & 1.59 \\
\hline 2 & & & & 380 & 0.83 \\
\hline 3 & 4 & $428(11)$ & $405-453$ & 445 & 0.57 \\
\hline 4 & 9 & $533(20)$ & $413-600$ & 502 & 0.44 \\
\hline 5 & 20 & $583(13)$ & $457-703$ & 553 & 0.36 \\
\hline 6 & 30 & $618(11)$ & $500-820$ & 599 & 0.31 \\
\hline 7 & 22 & $649(9)$ & $537-710$ & 639 & 0.28 \\
\hline 8 & 23 & $687(11)$ & $597-810$ & 675 & 0.25 \\
\hline 9 & 21 & $717(13)$ & $617-820$ & 707 & 0.24 \\
\hline 10 & 22 & $736(7)$ & $674-788$ & 735 & 0.22 \\
\hline 11 & 20 & $753(11)$ & $635-830$ & 760 & 0.21 \\
\hline 12 & 30 & $782(10)$ & $644-850$ & 783 & 0.21 \\
\hline 13 & 24 & $793(10)$ & $692-872$ & 803 & 0.20 \\
\hline 14 & 14 & $828(13)$ & $742-910$ & 821 & 0.19 \\
\hline 15 & 14 & $821(13)$ & $705-880$ & 836 & 0.19 \\
\hline 16 & 19 & 847 (13) & $754-960$ & 851 & 0.19 \\
\hline 17 & 7 & $874(11)$ & $840-915$ & 863 & 0.18 \\
\hline 18 & 8 & 871 (17) & $805-928$ & 874 & 0.18 \\
\hline 19 & 7 & $884(18)$ & $823-940$ & 884 & 0.18 \\
\hline 20 & 3 & $882(27)$ & $850-935$ & 893 & 0.18 \\
\hline 21 & 3 & $880(48)$ & $850-935$ & 901 & 0.18 \\
\hline 22 & 2 & $922(37)$ & $885-958$ & 908 & 0.18 \\
\hline 23 & & & & 914 & 0.17 \\
\hline 24 & 1 & 998 & & 920 & 0.17 \\
\hline 25 & 1 & 870 & & 924 & 0.17 \\
\hline 26 & & & & 929 & 0.17 \\
\hline 27 & & & & 933 & 0.17 \\
\hline 28 & 1 & 1000 & & 936 & 0.17 \\
\hline 29 & & & & 939 & 0.17 \\
\hline 30 & & & & 942 & 0.17 \\
\hline 31 & 1 & 900 & & 944 & 0.17 \\
\hline
\end{tabular}

17 